\title{
Prevalence and risk factors of the Bovine Thelaziasis at Mersa Town, Ethiopia
}

\author{
Mulat Asrat \\ School of Veterinary Medicine, Wollo University, Ethiopia. Email: mullur1974@gmail.com. \\ Copyright (@) 2017 Asrat. This article remains permanently open access under the terms of the Creative Commons Attribution License 4.0, which \\ permits unrestricted use, distribution, and reproduction in any medium, provided the original work is properly cited.
}

Received 2nd January, 2017; Accepted 1st February, 2017

\begin{abstract}
A cross-sectional study was conducted from April 2014 to June 2015 in the Mersa Town of South Wollo Zone, Amhara Regional State to determine the prevalence of Thelaziasis in cattle and to assess associated risk factors responsible for the occurrence of the disease. A total of 384 cattle of both ages (98 young and 286 Adult) with two sexes (203 males and 181 females) were grossly examined by flushing the conjunctival sacs and lachrymal duct with sterile saline solution. The prevalence of thelaziosis was $18.23 \%$ (70 cases). Age, sex, body condition scores and management systems did not show any statistical significant difference $(P>0.05)$ for the prevalence. The prevalence was higher in male $(24.12 \%)$, young $(26.53 \%)$, and extensively managed cattle $(20.69 \%)$ than their comparative female $(11.6 \%)$, adult $(18.38 \%)$, and semi-intensively kept animals (13.01\%) respectively. Regarding body condition scores, the highest prevalence of bovine Thelaziasis was recorded in poor body condition cattle (30.19\%) while the lowest was recorded in cattle with good body condition scores $(14.48 \%)$. The results of the present study showed that bovine thelaziosis requires special attention considering its impact on cattle production and productivity.
\end{abstract}

Key words: Cattle, eye worm, prevalence, Shawora Alfa, Thelaziosis.

\section{INTRODUCTION}

Ethiopia has the largest livestock inventories in Africa, including more than 38,749,320 cattle (Fubini, and Ducharme, 2004). Thelazia nematodes are commonly known as eye worms and cause ocular infections in animals. This genus of spirurids represents one of the most specific taxon among nematodes because of its very close relationship with its intermediate and final hosts (Otranto and Traversa 2005).

However, the immature and mature stages occur in the interior chamber of the eye, thereby being exposed to the external environment. Therefore, it could be considered an "ectoparasite". Sixteen species of this genus have been reported from ruminants. They have been documented in Europe (Italy, France, Switzerland and Germany), Asia (China, Japan, Korea and Taiwan), North America (Canada), South America (Peru) and South Africa. The adult worms live under the eyelids, nictitating membranes and in lacrimal ducts. Transmission depends upon the continuous presence of the vectors hence has a seasonal occurrence according to the seasonality of the intermediate hosts (Yang et al. 2006).
In final hosts, both the larval stages and adults of Thelazia spp. cause clinical signs such as excessive lacrimation, epiphora, conjunctivitis, keratitis and corneal ulcers (Otranto et al., 2001). A definitive diagnosis is made by detection of the parasites in the conjunctiva sac. Examination of lacrimal secretions may reveal eggs or first-stage larvae. Also, morphological differentiation has been done on some Thelazia species using scanning electron microscopy. Molecular characterization and phylogeny of some Thelazia species have been studied by Nadler et al. (2000), Otranto et al. (2001), and Traversa et al. (2005). Due to the localization of the nematode, thelaziosis can be treated topically by direct application of drugs into the eyes. Removal of the adult parasites with fine forceps, using local anasthesia is also helpful. Patients with an intraocular infestation with $T$. callipaeda have been successfully treated with Pars plana vitrectomy. Two $\mathrm{ml}$ of levamisole injected into the subconjunctival sac was more effective than levamisole given orally. Treatment of dog thelaziosis, caused by $T$. callipaeda, using a topical formulation of $10 \%$ imidacloprid and $2.5 \%$ moxidectin has 
has been studied by Bianciardi and Otranto (2005).

There are different diseases within the Alfa Shawora district that affect cattle which lead to loss of body condition, draft power and production. Among the eye infection, thelaziosis is the common problem within the district (MWARDO, 2006). So to put forward the major effect of Thelazia and to plan the control strategy, studying the problem within the district needs priority. Therefore, the objectives of this study were to determine the prevalence of bovine thelaziasis in Mersa Town, South Wollo Zone, Amhara Regional State and to assess associated risk factors involved for the occurrence of thelaziosis in cattle in the study area.

\section{MATERIALS AND METHODS}

\section{Study Area}

The study was conducted in Mersa Town, South Wollo Zone, Amhara Regional State, which is found in North West of Ethiopia and $491 \mathrm{~km}$ away from Addis Ababa. The rearing system of livestock population in the study area depends on natural grazing and crop residues and kept in the traditional management system. The physical feature of the Woreda is hilly, sloppy, plain area, rivers and forested. The altitude of the study area ranges from 1500 to 2500 meter above sea level with average annual temperature of 20 to $25^{\circ} \mathrm{C}$ (MWARDO, 2006).

\section{Study design and Sampling Methods}

A cross-sectional study was conducted from April 2014 to June 2015. The study animals were selected randomly from animals that were brought to Mersa town veterinary clinic and they were kept under individual households.

\section{Study Animals}

Cattle were categorized into groups on the basis of age group (young and adult), sex (male and female), breed (local and cross) (Aiello and Mays, 1998) and the body condition score (poor, medium and good) (Ferguson, 2011).

\section{Sample size determination}

The sample size requires for this study is determined based on sample size determined in random sampling for the infinite population using expected prevalence of $50 \%$ and $5 \%$ desired absolute precision according to Thrusfield (2005).

$\mathrm{n}=\frac{1.96^{2} \text { pex }(1-\text { pex })}{\mathrm{d}^{2}}$
Where: $\mathrm{n}=$ required sample size, pex $=$ expected prevalence and $\mathrm{d}^{2}=$ desired absolute precision.

Hence as for as the knowledge of the author concerned, there was no study did concerning thelaziasis of cattle in the study area, the sample size was estimated by using $50 \%$ expected prevalence with $95 \%$ confidence interval at $5 \%$ absolute precision (Thursfield, 1995).

\section{Statistical Analysis}

The data obtained from this survey were entered in Microsoft excel worksheet. Then descriptive statistics was used to analyze the data using statistical package for social sciences (SPSS) software version 20.0. Chi-Square test $\left(x^{2}\right)$ with computed $p$-value of less than 0.05 was used to estimate the statistical significance association of bovine thelaziosis rate with age, sex, body condition score, management system and altitude differences.

\section{RESULTS}

Out of the total 384 cattle examined, 70 (18.23\%) were found positive for bovine thelaziosis after a thorough examination.

\section{Age-based prevalence}

The prevalence of the disease was higher in the age group of younger $(26.53 \%)$ than adult $(18.38 \%)$. However, no any significance difference $\left(x^{2}=5.113, p=0.203\right)$ between the age groups (Table 1).

\section{Sex- based prevalence}

The prevalence of bovine thelaziosis in male cattle $(24.12 \%)$ was found greater than in females $(11.6 \%)$. There was also no significant difference $\left(x^{2}=2.149\right.$, $\mathrm{p}=0.716$ ) between both sex groups (Table 2 ).

\section{Body conditions scores based prevalence}

The prevalence of bovine thelaziosis in poor body condition cattle $(30.19 \%)$ higher than that of medium body condition (17.79\%) as well as good body condition $(14.88 \%)$. There was no statistically significant difference $\left(x^{2}=1.867, p=0.445\right)$ (Table 3).

\section{Management system based prevalence}

The prevalence of the disease was found higher in the extensive management system $(20.69 \%)$ than in semiintensive management system (13.01\%). However, there 
Table 1. Prevalence of bovine thelaziasis at Mersa Town, Ethiopia according to age.

\begin{tabular}{|c|c|c|c|c|c|}
\hline Age & No. of cattle examined & No. of positive cattle & Prevalence (\%) & $X^{2}$ value & P-value \\
\hline Young & 98 & 26 & 26.53 & & \\
\hline Adult & 286 & 44 & 18.38 & 5.113 & 0.203 \\
\hline Total & 384 & 70 & & & \\
\hline
\end{tabular}

Table 2. Prevalence of bovine thelaziasis at Mersa Town, Ethiopia according to sex.

\begin{tabular}{lccccc}
\hline Sex & No. of cattle examined & No. of positive cattle & Prevalence (\%) & $\mathbf{X}^{2}$ value & P- value \\
\hline Male & 203 & 49 & 24.12 & & \\
Female & 181 & 21 & 11.6 & 2.149 & 0.716 \\
Total & 384 & 70 & & & \\
\hline
\end{tabular}

Table 3. Prevalence of bovine thelaziasis at Mersa Town, Ethiopia according to body condition score.

\begin{tabular}{|c|c|c|c|c|c|}
\hline Body condition score & No. of cattle examined & No. of positive cattle & Prevalence (\%) & $X^{2}$ value & P-value \\
\hline Poor & 53 & 16 & 30.19 & \multirow{4}{*}{1.867} & \multirow{4}{*}{0.445} \\
\hline Medium & 163 & 29 & 17.79 & & \\
\hline Good & 168 & 25 & 14.88 & & \\
\hline Total & 384 & 70 & & & \\
\hline
\end{tabular}

Table 4. Prevalence of bovine thelaziasis at Mersa Town, Ethiopia according to management system.

\begin{tabular}{|c|c|c|c|c|c|}
\hline Management system & №. cattle examined & No. positives cattle & Prevalence (\%) & $\mathrm{X}^{2}$ value & P-value \\
\hline Extensive & 261 & 54 & 20.69 & & \\
\hline Semi-intensive & 123 & 16 & 13.01 & 0.158 & 0.373 \\
\hline Total & 384 & 70 & & & \\
\hline
\end{tabular}

was no significance difference between two management systems of cattle $\left(x^{2}=0.158, p=0.373\right)$ (Table 4$)$.

\section{DISCUSSION}

The overall prevalence of bovine Thelaziosis was $18.23 \%$. Despite the fact that no cases of bovine thelaziosis have been reported in the study area, this survey suggests that these parasites were relatively extensive. Prevalence of bovine Thelaziosis reported in this study was less than the prevalence of $22 \%$ reported in cattle in endemic areas (Tweedle et al., 2005).

The current study indicated there was no significant difference between age groups but higher infection rate was found in young $26.53 \%$ than in adult cattle $18.38 \%$. However, it contradicts with the work of Van Aken et al. (1996) who reported that no age and sex preference of cattle in cases exposed to thelaziosis in cattle. The increased prevalence of young animals might be due to the fact that young cattle are not allowed to go far with adult animals for grazing and increased a chance of exposure to vectors around the barn which is a suitable habitat for the vector that results in a high fly density and transmission of the disease.

The study result showed that there was no significant difference in prevalence due to a difference in sex. This finding was in line with the results of Gutierres et al. (1980) who opined that both sexes have an equal chance of exposure for thelaziosis.

The highest prevalence of thelaziosis in cattle was observed in poor body conditioned (30.19\%) cattle followed by medium body conditioned cattle (17.79\%) while the lowest prevalence observed in cattle with good body condition (14.88\%). This might be associated with the fact that effect of parasites can be influenced by animals on an inadequate diet which can influence the level of immunity.

Higher level prevalence of thelaziosis was observed in cattle kept in the extensive management system (20.69\%) compared to cattle kept in semi-intensive management system (13.01\%). The result in this study was in agreement with the work of Giangaspero et al. (2000) who reported that thelaziosis infections were not found in 
cattle from herds managed indoors. The reason might be associated with exposure to transmitting vectors as cattle kept indoors are less exposed to face flies.

\section{Conclusion and Recommendations}

The result of the current study with prevalence of $18.23 \%$ indicated that the disease is prevalent in the study area. The age, sex, body condition score and management system were not found to have significant influence on the prevalence of Thelaziosis in cattle.

The parasite is known by farmers affecting their cattle and they were trying to control it by using traditional practices and modern treatments. Sex, age, group, body condition, and management system of the area are important factors affecting occurrence of thelaziosis in cattle. High level of prevalence observed in male, five years and above old emaciated and extensively kept in low land.

Based on the above conclusion, the following recommendations are forwarded:

1. Awareness creation for the farmers should be given to the transmission and condition when flies are highly invested.

2. Integrated prevention and control strategies of the disease should be given and.

3. Further studies should be conducted in the study area of assessing the species of the parasite and vectors as well as their seasonal dynamics and economic impact of the disease.

\section{CONFLICT OF INTEREST}

The authors declare that they have no conflict of interest.

\section{REFERENCES}

Aiello, S. E., \& Mays, A. (1998). The Merck veterinary Manual. $8^{\text {th }}$ ed. Merck and Coted. Inc., White house, NJ. USA. Pp. 131-140.

Bianciardi, P., \& Otranto, D. (2005). Treatment of dog thelaziosis caused by Thelazia callipaeda (Spirurida, Thelaziidae) using a topical formulation of imidacloprid $10 \%$ and moxidectin $2.5 \%$. Veterinary parasitology, 129(1), 89-93.

Ferguson, J. D. (2011). Review of body condition scoring dairy herd. Available at: http://www.txanc.org/wpcontent/uploads/2011/.../Body-Condition-Scoring.pdf. Accessed on 23 November, 2013.
Fubini, S. L., \& Ducharme, N. G. (2004). Surgery of ruminant fore-stomach compartment. Saunders, Elsevier, 161-240.

Giangaspero, A., Otranto, N., Vovlas, R. \&Puccini, V. (2000). Thelaziagulosa Railliet and Henry, 1910 and $T$. skrjabiniErschow, 1928 infection in southern Europe (Italy). Parasite, 7, 327-329.

Gutierres, V. C., Onama, R. K., \& Todd, A. C. (1980). Prevalence of the eyeworms Thelazia gulosa (Railliet and Henry, 1910) and T. skrjabini (Erschow, 1928) in Wisconsin dairy cattle. Journal of Parasitology, 66(2), 304.

MWARDO, (2006). Mersa Woreda Agricultural and Rural development Office Annual report (2004).

Nadler, S. A., Hoberg, E. P., Hudspeth, D. S., \& Rickard, L. G. (2000). Relationships of Nematodirus species and Nematodirus battus isolates (Nematoda: Trichostrongyloidea) based on nuclear ribosomal DNA sequences. Journal of Parasitology, 86(3), 588-601.

Otranto, D., \& Traversa, D. (2005). Thelazia eyeworm: an original endo-and ecto-parasitic nematode. Trends in parasitology, 21(1), 1-4

Otranto, D., Tarsitano, E., Traversa, D., Giangaspero, A., De Luca, F., \& Puccini, V. (2001). Differentiation among three species of bovine Thelazia (Nematoda: Thelaziidae) by polymerase chain reaction-restriction fragment length polymorphism of the first internal transcribed spacer ITS-1 (rDNA). International journal for parasitology, 31(14), 16931698.

Thrusfield, M., (1995). Veterinary Epidemiology, $3^{\text {rd }}$ ed. Blackwell publishing, London.Black Well Science Ltd. 150-192.

Traversa, D., Otranto, D., Iorio, R., \& Giangaspero, A. (2005). Molecular characterization of Thelazia lacrymalis (Nematoda, Spirurida) affecting equids: a tool for vector identification. Molecular and cellular probes, 19(4), 245-249.

Tweedle, D. M., Fox, M. T., Gibbons, L. M., \& Tennant, K. V. (2005). Change in the prevalence of Thelazia species in bovine eyes in England. Veterinary record, 157(18), 555-556.

Van Aken, D., Dargantes, A. P., Lagapa, J. T., \& Vercruysse, J. (1996). Thelazia rhodesii (Desmarest, 1828) infections in cattle in Mindanao, Philippines. Veterinary parasitology, 66(1-2), 125-129.

Yang, Y. J., Liag, T. H., Lin, S. H., Chen, H. C., \& Lai, S. C. (2006). Human thelaziasis occurrence in Taiwan. Clinical and Experimental Optometry, 89(1), 40-44. 